\title{
Physical Demands of Top-class Soccer Assistant Refereeing during High-standard Matches
}

Authors

Affiliations

Key utords

Q 2D-analysis

association footbal

Q ball displacements

0 high-intensity activities

o heart rate

\author{
J. Mallo', E. Navarro', J. M. Garcia Aranda', W. Helsen ${ }^{3}$ \\ ${ }^{1}$ Facultad Clenclas Activldad Física y el Deporte, Laboratorio de Biomecánica, Madrid, Spain \\ ${ }^{2}$ Referees Department, Federation International de Football Association, Zurich. Switzerland \\ ${ }^{3}$ Biomedical KInesiology, Katholieke Universiteit Leuven, Heverlee, Beiglum
}

\begin{abstract}
This study examined the physical demands experienced by top-class assistant referees during high-standard football matches. Computerized match analyses and heart rate recordings were performed on 18 international assistant referees during the FIFA Confederations Cup 2005. Total distance covered averaged $5752 \pm 554 \mathrm{~m}$, of which $34 \%$ was covered at a high-intensity $\left(>13 \mathrm{~km} \cdot \mathrm{h}^{-1}\right)$. Sidewards movements represented $30 \%$ of total match distance. Both total distance $(r=0.67 ; P<0.01)$ and high-intensity activities $(r=0.52 ; \mathrm{P}<0.05)$ were related to the

displacements of the ball in the same match. The distance covered by higli-speed running in this tournament was $255 \%$ greater $(\mathrm{P}<0.001)$ than that covered during the under- 17 World Chanpionship 2003. Mean heart rate during the game was $140 \pm 11 \mathrm{~b} \cdot \min ^{-1}\left(78 \pm 4 \% \mathrm{HR}_{\max }\right)$. Mean heart rate during a 5-min interval of the match was related in part $(\mathrm{r}=0.31 ; \mathrm{P}<0.001)$ to the amount of high-intensity activities performed within the same match-period. The results of this study show that the physical demands imposed on assistant referees are influenced by the movements of the ball and the standard of the competition.
\end{abstract}

\section{Heteroduction}

\section{$\nabla$}

The activity profile and physiological strain imposed on football referees have attracted more and more interest over the last years $[8,9,14,18,23,25]$. Surprisingly, little attention has being paid to the physical requirements of assistant refereeing. Referees governing bodies have traditionally grouped together assistant referees with referees for training and testing purposes. However, recent studies $[13,15,19]$ have shown that they should be considered as an independent population because of the unique physical demands they are exposed to during match-play.

Using different match analysis computerized systems, Krustrup et al. [15] and Mallo et al. [19] reported that assistant referees covered around $6-7 \mathrm{~km}$ during a match, with $16-20 \%$ of this distance covered by high-intensity activities. The use of heart rate monitors is a widely extended tool to determine the exercise intensity in a variety of sports [2] and have been employed by assistant referees during real match-play, with a mean heart rate of $137-140 \mathrm{~b} \cdot \mathrm{min}^{-1}(77 \%$ of the individual maximal heart rate: $\left.\mathrm{HR}_{\max }\right)[12,15]$.
Nevertheless, the determination of these kinematical and cardiovascular parameters has been carried out independently. It remains uncertain if there is a relationship between the movement patterns and the cardiovascular response in assistant referees. If this was the case, the use per se of heart rate monitoring during a match could help predicting the global intensity of any match performance and developing training programmes specific to the demands experienced during the game.

The physical performance of football players and referees during a match can be affected by a variety of factors such as fatigue $[4,6,20]$, the level of the players $[7,16,20,25]$ or the playing style of the teams $[21,26]$. To date, the kinematical demands placed on assistant referees have only been examined during domestic Danish league games [15] and top-level under-17 matches [19]. It is still unclear to what extent the participation of top-level football players would affect the physical response of the assistant referees. It would be expected that officiating at a higher competitive level would raise the kinematical demands of assistant referees to keep up with the game and to judge the play from the most appro- 
priate viewing angle. Additionally, Mallo et al. [17] found a relationship between the movements of the ball and the distance . covered and high-intensity activities performed by the referee within the same match. It would be of interest to determine if this was the case also for the assistant referees.

Thus, the aim of the present study was to examine and synchronize the kinematical and heart rate response of top-level assistant referees during an international high-standard senior FIFA tournament. An additional purpose was to investigate the effect of the level of the competition and the displacements of the ball on the kinematical performance of the assistant referees.

\section{Phethods \\ ฟ}

\section{Participants}

Eighteen top-level male assistant referees of mean age $38.67 \pm 4.75$ years, mean height $1.77 \pm 0.07 \mathrm{~m}$ and mean body mass $75.11 \pm 8.63 \mathrm{~kg}$ participated in the study. All of them were licensed by the Fédération Internationale de Football Association (FIFA) and had an average of five years of experience at international level. Written consent from the Referee's Committee and from all the subjects was obtained priot to participation in the study after an explanation of the nature of the research.

\section{Experimental design}

Ali measurements were carried out in a two-week period during the FIFA Confederations Cup held in Germany in June 2005. The kinematical activity of 18 assistant referees was determined in 9 matches of the tournament, whereas 22 match observations were obtained from monitoring the heart rate response. Both the kinematical parameters and the heart rate responses were simultaneously recorded in 14 officials.

The data from this study were compared with those obtained during the FIFA under-17 World Championship 2003 [19] that embraced 24 match observations performed on top-class assistant referees $(34.03 \pm 2.93$ years; $1.76 \pm 0.07 \mathrm{~m} ; 73.32 \pm 7.95 \mathrm{~kg}$ ). The same methodology for match analysis was employed in both tournaments.

\section{Match analysis}

The matches were filmed using three JVC GY-DV500E fixed cameras positioned in the last row of the main stand of the stadiums and the videotapes were later replayed, synchronized and stored on the hard-disk of a computer. Computerized analysis of the frames was carried out and the vertical projection of the assistant referee's center of mass was indicated with the mouse on the computer screen at a frame rate of $1 \mathrm{~Hz}$. $[18,19]$. The position of the ball, where it was on the ground, was also digitized during the match. Whenever the ball was played in the air, the ball was not digitized and only the initial and final positions were indicated on the screen. This allowed the calculation of the horizontal distance between both positions. After digitizing the calibration system for each of the cameras, two-dimensional DLT-based algorithms [1] were used to transform the screen displayed units to metres. These coordinates were smoothed using quintic-spline functions with the Cross-Generalized Validation procedure as a means of evaluating the adjustment factor [27]. The displacement and speed of the assistant referee were calculated from the spline polynomial functions and classified into the following locomotive categories [based on 18]: (i) standing stilt $\left(<3.60 \mathrm{~km} \cdot \mathrm{h}^{-1}\right)$; (ij) walking $\left(3.61-7.20 \mathrm{~km} \cdot \mathrm{h}^{-1}\right)$; (iii) jog- ging (7,21-13 km.h-1); (iv) cruising (13.01-18 $\left.\mathrm{km} \cdot \mathrm{h}^{-1}\right)$ and (v) high-speed running ( $>18 \mathrm{~km} \cdot \mathrm{h}^{-1}$ ). The movements performed at speeds exceeding $13 \mathrm{~km} \cdot \mathrm{h}^{-1}$ were entitled as high-intensity activities. The displacements were also classified into forward and sidewards movements for further analysis. Performance throughout the match was computed in 5-, 15- and 45-min intervals.

All the offside situations indicated by the assistant referees during the match were analyzed at a frame rate of $25 \mathrm{~Hz}$. In the frame in which the offside occurred, that is, when the bal! was passed by the attacker, the position of the assistant referee and the second-last defender were digitized on the screen and the horizontal distance between both positions calculated. This second-last defending player determines the theoretical offside line and the FIFA Referee's Committee encourages assistant referees to be as close as possible to it in order to be able to follow the play and judge precisely these offside situations. When the assistant referee was behind the offside line these distances were considered as negative values. On the other hand, when the assistant referee was moving ahead of the second-last defender these distances were measured as positive values. Previous research [19] has reported the validity and reproducibility of this method for match analysis. The Root Mean Square error [3] for reconstructed distances between two points was less than $2 \%$. When the distance covered by sportsmen who followed typical movement patterns of assistant referees during a match at paced speeds was compared to the one that was reconstructed with the actual photogrammetric technique, differences were not significant $(P>0.05)$ and less than $2 \%[19]$. Specifically, the difference for the high-speed rumning category was $1.61 \%$, whereas for the intermittent exercise category (reproducing match-day activity ratios) was $0.5 \%$. No differences $(P>0.05)$ were detected in the intra- and inter-rater reliability tests, with total differences in the kinematical data always being less than $1 \%$.

\section{Heart rate}

Heart rate was recorded at 5-s intervals during the matches using Polar Team System (Polar Electro Oy, Kempele, Finland) heart rate monitors. At the end of the match the data were downloaded to a computer and processed using the Polar Precision 3.0 software (Polar, Kempele, Finland). The heart rate data were expressed in relation to the individual $\mathrm{HR}_{\max }$ and, after Helsen \& Buitynck [13], classified into the following categories: (i) $<65 \% \mathrm{HR}_{\text {max }}$; (ii) $66-75 \% \mathrm{HR}_{\text {maxi }}$ (iii) $76-85 \% \mathrm{HR}_{\text {max }}$ (iv) $86-$ $95 \% \mathrm{HR}_{\max }$ and $>95 \% \mathrm{HR}_{\max }$. The indivual $\mathrm{HR}_{\max }$ was determined as the peak value reached in any match, training session and fitness test carried out by the assistant referee.

\section{Statistical analysis}

Data are reported as means \pm standard deviation (SD). Differences between two means were tested for significance using dependent $t$-tests. Differences between the physical performances in 5- and 15-min intervals within the match were evaluated using repeated measures analysis of variance (ANOVA). When a significant interaction was detected, data were subsequently analyzed using a Newman-Keuls post hoc test. For the analysis of match activities, heart rate response and match standard, two-way repeated measures ANOVA were performed. When a significant F-value was found, Bonferroni's post hoc test was applied. Correlation coefficients were determined and tested for significance using a Pearson's product-moment test. 
Table 1 Distance covered $(m)$ by different match activities during both halves of a match (mean \pm SD).

\begin{tabular}{lccc} 
& First Half & Second Half & \multicolumn{1}{c}{ Overall } \\
standing still & $411 \pm 39$ & $397 \pm 40$ & $808 \pm 70$ \\
walking & $683 \pm 73$ & $685 \pm 105$ & $1368 \pm 144$ \\
Jogging & $844 \pm 115$ & $763 \pm 119^{*}$ & $1608 \pm 211$ \\
cruising & $489 \pm 116$ & $433 \pm 70^{*}$ & $922 \pm 158$ \\
high-speed running & $547 \pm 188$ & $500 \pm 207$ & $1047 \pm 342$ \\
total & $2973 \pm 343$ & $2779 \pm 303$ & $5752 \pm 554$
\end{tabular}

*Significant difference $(P<0.05)$ from first half. *Significant difference $(P<0.01)$ from first half

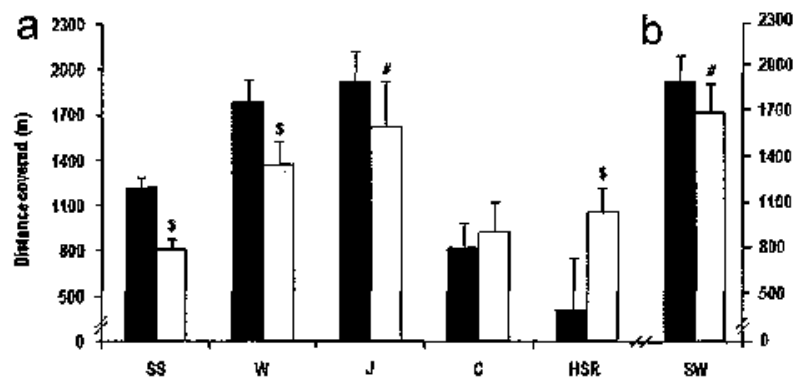

Fig. 1 Distance covered (a) at different speeds and (b) by sidewards movements during the FIFA under-17 World Championship 2003 (dark bars) and the FIFA Confederations Cup 2005 (light bars). "Significant difference $(\mathrm{P}<0.01$ ) from under-17 WC. "Significant difference ( $\mathrm{P}<0.001)$ from under-17 WC. SS=5tanding Still, $W=$ Walking, $J=$ logging,

C=Cruising, HSR=High-speed rinning, SW: Sidewards movements.

Significance was chosen at $\mathrm{P}<0.05$ for all the statistical tests. The meaningfulness of the difference between two means was determined by the effect size ((mean 1-mean 2).SD-1) [24]. All the calculations were carried out with the software Statistical Package for the Social Sciences (SPSS 13.0).

\section{Results}

$\nabla$

\section{Distance covered}

The mean distance covered during a match was $5752 \pm 554 \mathrm{~m}$. During the first half the assistant referees covered a greater distance ( $P<0.05$; effect size; 0,60 ) than in the second $45-\mathrm{min}$ of the match: $2973 \pm 343$ vs. $2779 \pm 303 \mathrm{~m}$, respectively.

\section{Watch activities}

- Table 1 summarizes the distance covered by different match activities, according to the speed of the displacements. The results of the two-way ANOVA detected an effect for the activity categoly $\left(\mathrm{F}_{4,68}=52.54 ; \mathrm{P}<0.001\right)$ and for the match period $\left(F_{1,17}=6.00 ; P<0.05\right)$. In the second half of the match the assistant referees decreased the distance covered by jogging $(P<0.01$; effect size: 0.69 ) and cruising ( $\mathbf{P}<0.05$; effect size: 0.58 ). On average, the assistant referees stood still for $48.3 \pm 3.4 \%$, walked for $24.6 \pm 2.6 \%$, jogged for $16.6 \pm 1.8 \%$, cruised for $6.1 \pm 1.1 \%$ and ran at high-speeds for $4.4 \pm 1.4 \%$ of the total playing time.

Sidewards movements amounted to $29.7 \pm 4.7 \%(1706 \pm 177 \mathrm{~m})$ of total match distance, with no differences $(P>0.05)$ between the two halves.
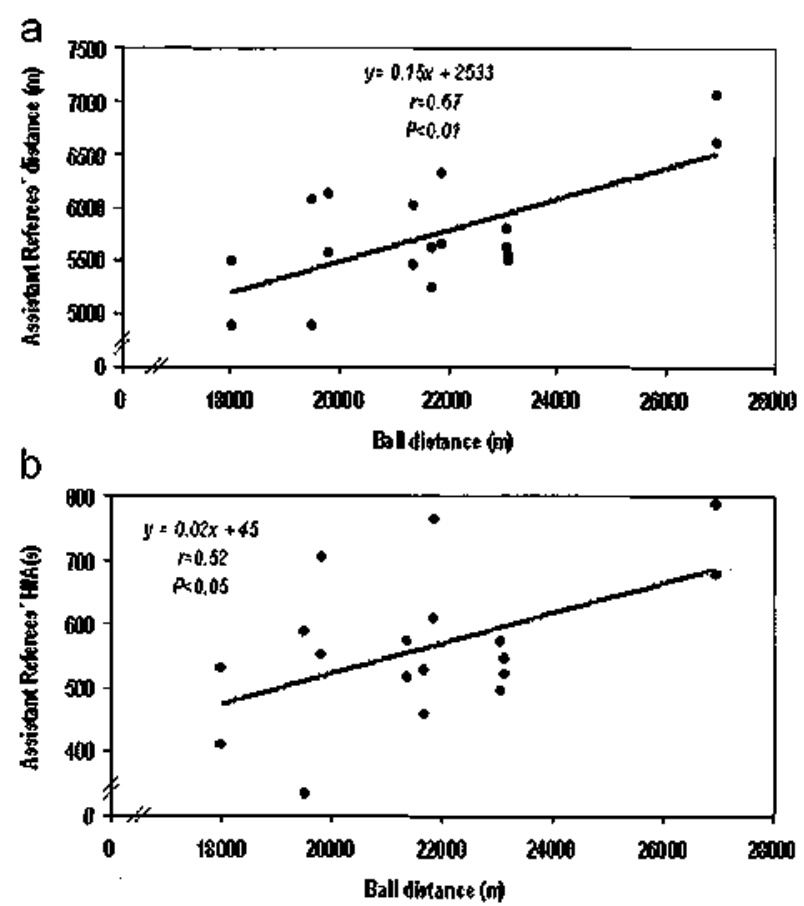

Fig. 2 a Ind|v|dual relattonship between distance covered by the assistant referee and by the ball durlng the match. $\mathbf{b}$ Individual relationship between high-intensity activities performed by the assistant referee and distance covered by the ball during the match.

\section{Match standard}

The distance covered at different speeds during the under-17 World Championship 2003 and the Confederations Cup 2005 is presented in 0 Fig. 1a. The results of the two-way ANOVA revealed an effect for match standard $\left(F_{1,40}=4.60 ; \mathrm{P}<0.05\right)$ as assistant referees covered greater distance in the youth $(6137 \pm 539 \mathrm{~m})$ than in the senior championship $(5752 \pm 554 \mathrm{~m})$. Additionally, the two-way ANOVA yielded a match standard $x$ period interaction $\left(F_{4,160}=61.46, P<0.001\right)$. From 0 Fig. $1 \mathrm{a}$ it is clear than the assistant referees covered greater distance at low (standing still and walking; $P<0.001$; effect size: 5.98 and 2.81 , respectively) and medium (jogging; $\mathrm{P}<0,01$; effect size: 1.11) intensities during the under- 17 World Championship, whereas they ran further at high speeds ( $P<0.001$; effect size: 2.48 ) during the Confederations Cup. Distance covered by sidewards movements was greater ( $\mathbf{P}<0.01$; effect size: 1.09 ; $\mathbf{~ F i g . ~ 1 b ) ~ i n ~}$ the under-17 World Championship than in the Confederations Cup.

\section{Distance covered by the ball}

There was no difference $(P>0.05)$. regarding the distance travelled by the ball in both halves of the match, as the ball covered $11009 \pm 1735$ and $10706 \pm 1096 \mathrm{~m}$ during the first and second half, respectively. The distance covered by the assistant referees was related $(\mathrm{r}=0.67 ; \mathrm{P}<0.01 ; 0$ Fig. $2 \mathrm{a}$ ) to the distance covered by the ball in the same match. In addition, the amount of highintensity activities were also related $(r=0.52 ; P<0.05 ;$ Fig. $2 b)$ to the distance travelled by the ball.

\section{Distance from offside situations}

A total of 35 offside situations were observed and replayed for further analysis. The absolute mean distance to the offside line 


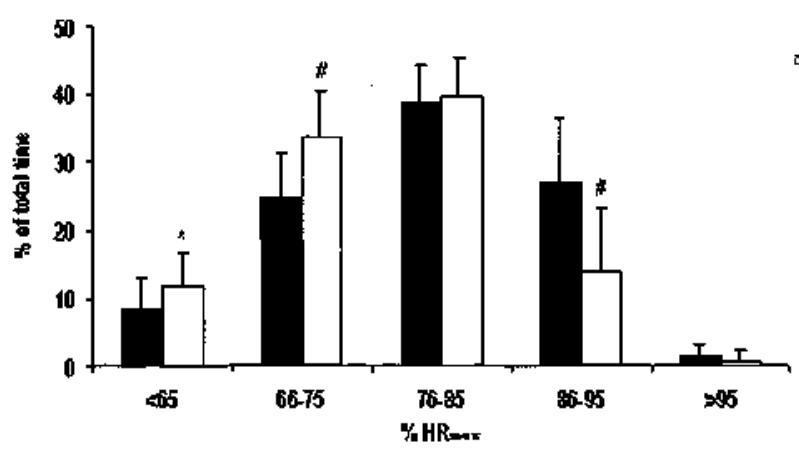

Fig. 3 Percentage of time spent at different intensities (in relation to

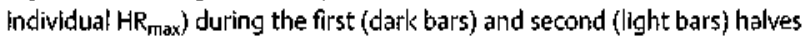
of the match. *Significant difference $(P<0.05)$ from first half. "Significant difference $(P<0,01)$ from first half.

was $0.64 \pm 0.49 \mathrm{~m}$. In 17 of the 35 situations the assistant referee was behind the second-last defender, with a mean distance of $-0.50 \pm 0.43 \mathrm{~m}$, whereas in the remaining 18 situlations the assistant referee was $0.78 \pm 0.51 \mathrm{~m}$ ahead of the offside line. The assistant referee showed the tendency $(P=0.091)$ to be farther away from the offside line, at the moment of the pass, when he was running ahead rather than behind the second-last defender.

\section{Heart rate}

Mean heart rate during a match was $140 \pm 11 \mathrm{~b} \cdot \min ^{-1}$, which corresponded to $78 \pm 4 \%$ of the individual $\mathrm{HR}_{\max }$. The mean heart rate decreased $(\mathrm{P}<0.01)$ from $143 \pm 13$ to $137 \pm 11 \mathrm{~b} \cdot \mathrm{min}^{-1}$ between halves. On average, assistant referees spent $10.3 \pm 7.1 \%$ of total match-time exercising at intensities below $65 \%$ of indjvidual $\mathrm{HR}_{\max }$, whereas $30.6 \pm 10.4 \%$ and $39.4 \pm 9.7 \%$ was spent within $66-75 \%$ and $76-85 \% \mathrm{HR}_{\max }$, respectively. The remaining playing time was spent between $86-95 \%(19.2 \pm 12.7 \%)$ and $>96 \%$ $\mathrm{HR}_{\text {max }}(0.5 \pm 0.7 \%)$. Fig. 3 provides an overview of the differences between halves. The results of the two-way ANOVA yielded an effect for the activity category $\left(\mathrm{F}_{4.84}=39.06 ; \mathrm{P}<0.001\right)$ as wel] as for the activity category $x$ period interaction $\left(\mathrm{F}_{4,84}=7,26\right.$; $P<0.001$ ). In the second half of the game, while the assistant referees increased the time spent within $<65 \%(\mathrm{P}<0.05)$ and $66-$ $75 \% \mathrm{HR}_{\max }(\mathrm{P}<0.01)$, there was a decrease in the activities performed at intensities exceeding $85 \% \mathrm{HR}_{\max }$, that is within $86-95 \%(P<0.01)$ and $>96 \% \mathrm{HR}_{\max }(\mathrm{P}=0.06)$.

\section{Individual relationship between heart rate and match activities}

An individual relationship was found between the mean heart rate (expressed as a percentage of $\mathrm{HR}_{\max }$ ) and the amount of high-intensity activities performed by the assistant referee within the same 5 -min interval of the match $(\mathrm{F}=0.31 ; \mathrm{P}<0.001$; o Fig. 4).

\section{Discrussion \\ $\checkmark$}

The results of this study show that the overall physical demands imposed on top-class assistant referees during a match can be considered as moderate, as total distance covered ouring the FIFA Confederations Cup ranged $5-7 \mathrm{~km}$ with a mean cardiovas-

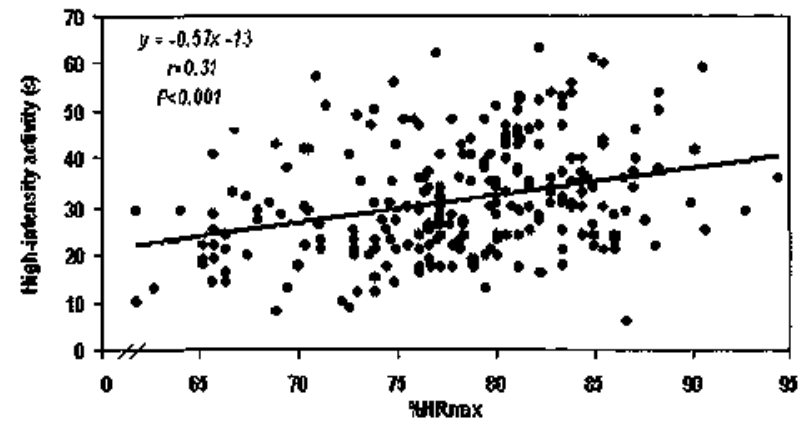

Fig. 4 Indlvidual relationship between the mean heart rate (expressed as\% $\mathrm{HR}_{\max }$ ) and the amount of high-intensity activities performed within the same 5 -min interval of the match.

cular load of $78 \% \mathrm{HR}_{\max }$. However, almost $30 \%$ of match distance was covered by sidewards movements. In addition, assistant referees were exposed to short periods of intense exercise as $10 \%$ of match time was spent on cruising and high-speed running, with $20 \%$ of the match exercising at intensities exceeding $85 \%$ $\mathrm{HR}_{\max }$. Both total distance covered and high-intensity activities performed during a match were related to the distance travelled by the ball, suggesting the need of assistant referees to adapt to the tempo of the game imposed by the players. The volume of high-speed running performed during a match seems to be different for various levels of competition. Altogether, this parameter characterizes best the physical performance capacity of assistant referees. Finally, we observed a moderate relationship between mean heart rate and high-intensity activities performed within the same 5-min interval, which suggested that the monitoring of heart rate can be an additional variable to help to disclose the most intense periods of the match.

Total distance covered by the assistant referees showed an average value of $5.8 \mathrm{~km}$, with a mean heart rate of $140 \mathrm{~b} \cdot \mathrm{min}^{-1}$, which corresponded to $78 \%$ of the individual $\mathrm{HR}_{\mathrm{max}}$. These parameters are in line with the literature $[12,15,19]$ but should only be used as raw estimators of the global exercise intensity experienced when assistant refereeing. To better understand the requirements of the game it is essential to examine the activity profile, attending to the direction and the speed of the movements. Mean distance covered by sidewards movements was $1.7 \mathrm{~km}$. This unorthodox mode of locomotion has been shown to be more energy demanding than forward displacements [22] and it is essential to keep up with the offside line during competition [15]. In relation to the speed of the movements, assistant referees covered, on average, $2.2,1.6$ and $2 \mathrm{~km}$ at low$\left(<7.2 \mathrm{~km} \cdot \mathrm{h}^{-1}\right)$, medium- $\left(7.21-13 \mathrm{~km} \cdot \mathrm{h}^{-1}\right)$ and high$\left(>13 \mathrm{~km} \cdot \mathrm{h}^{-1}\right)$ intensities, respectively. These high-intensity activities were related in part to the heart rate recordings within the same 5 -min interval of the match. The distance covered by different match activities in the present study were compared with those reported in a previous study [19] carried out in a youth top-level tournament ( $\$$ Figs. 1a, b). The level of the competition had an important effect on the physical demands imposed on the assistant referees, as they had to run at bighspeeds as much as 2.5 times further (effect size: 2.48 ) during a high-standard competition compared to a top-level under-17 tournament. This observation highlights the importance for assistant referees to produce maximal and repeated activities to 
keep up with the pace of the game imposed by top-class players that perform 28 and 58\% more high-intensity running and sprinting than moderate level players [20]. On the other hand, sidewards movements were inferior in the Confederations Cup. which could represent a movement strategy of top-class referees to spare energy for the most demanding episodes of the match. Distance covered and high-intensity activities performed by the assistant referees were moderately related to the distance travelled by the ball within the same match. From a practical point of view, this observation would mean that the style of play of the teams had an effect on the physical demands imposed on the officials, reinforcing recent studies [26] that have reported that match activities of referees were partly related to those of the players. While controlling the distance covered by the ball, it would be of interest in future research to determine the speed at which the ball is played, as this speed dictates the tempo of the play and elevates the demands experienced by both referees and assistant referees to follow the game. It is be reasonable to conceive that top-class players would play the ball at a faster speed than moderate level players.

In addition to the level of the competition, the distance covered by the ball and the match activies carried out by the players, another factor that can affect the physical performance of the assistant referees during a match is the development of fatigue [15]. The assistant referees observed in this study showed a decrease in total distance covered and mean heart rate after halftime, whereas the amount of sidewards movements and high-speed running was unaltered, which could suggest that top-class officials seem to have developed skills to avoid physical underperformance in the final stages of the match [9]. Additionally, we did not detect an impairment of performance after the most intense episodes of each half. After reaching the 5-min peak high-intensity activity of the match $(48 \pm 10 \mathrm{~s})$ in the following 5-min interval the amount of this intense activity was only reduced $4 \%(P>0.05)$ in relation to the mean of the match. These results suggest that the alternative characteristics of the play allows the assistant referee to partially recover when the balt is played in the other side of the field. These strategies to reduce the impairment of the kinematical performance are specially important when assistant refereeing at high-standard competitions, where officials confront players that are full-time professionals, around 10 years younger [5] and can be substituted when they become fatigued [20].

To be able to judge the offside positions assistant referees need to adopt a critical point of view in the field [13]. In the present study, we differentiated between when the assistant referee was behind or ahead of the offside line at the moment the ball was passed. On average, assistant referees were $0.64 \mathrm{~m}$ away from the offside line, which is a closer value than the $1.36 \mathrm{~m}$ calculated during the under-17 2003 World Championship [19]. This was probably due to the higher level of the officials involved in the Confederations Cup. The assistant referee was nearer $(P=0.091)$ to the offside line when he was moving behind the second-last defender rather than ahead. Furthermore, while controlling the distance from the offside line, information regarding the accuracy of the decision is also highly relevant. Investigations about the decision-making process both in referees [e.g. 10] and assistant referees [e.g. 11,13], related to their positioning in the field, seems a future challenge for sports scientists, in order to gain greater understanding about the technical aspects of refereeing.
In summary, the present study shows that assistant referees have to produce frequent bouts of sidewards movements and ohigh-speed running to follow the play. The physical demands experienced by these officials are dependent on the level of the competition and can be influenced by the distance covered by the ball, that is, the style of play of teams. We found that during high-standard competitive matches assistant referees have to perform more high-speed running to keep up with the pace of the game than when officiating top-level under-17 matches. in addition, both the total distance covered and the amount of high-intensity activities were related to the distance covered by the ball during the match.

\section{Aclsmowledgements \\ \$}

This study was supported by the Refereeing Department of the Fédération Internationale de Football Association. The cooperation of the referees and assistant referees was also of invaluable importance.

\section{References}

1 Abdel-Aziz YI, Karara HM. Direct linear transformation from comparator coordinates into space coordinates in close range photogrammetry. In; The American Society of Photogrammetry, ed. Proceedings of the Symposium on close range photogrammetry. Falls Church; 1971; 1-18

2 Achten J. Jeukendrup AE, Heart rate monitoring. Applications and limitations. Sports Med 2003; 33: 517-538

3 Allard $P$, Blanchi JP, Aissaqui R. Bases of three-dimensional reconstruction. In: Allard P, Stokes IAF, Bianchi JP, eds. Three dimensional anaIysis of human movement. Champaign, IL: Human Kinetics; 1995; $19-40$

4 Bangsbo J, Norregaard L, Thorso F. Activity profile of competition soccer. Can J Sport Sci 1991; 16: 110-116

5 Bloomfield $\mathrm{J}$, Polman $R, O$ 'Donoghue $P G$. Analysis of body composition of players of four major European leagues. J Sports Sci 2004; 22; 525-526

6 Castagna C, D'Ottavio S. Effect of maximal aerobic power on match performance in elite soccer referees. J Strength Cond Res 2001; 15: $420-425$

7 Castagna C, Abt G, D'Ottavio S. Activity profile of international-level soccer referees during competitive matches.J Strength Cond Res 2004; 18: $486-490$

8 Castagna $C, A b t G, D^{\prime} O t t a v i o ~ S$. Physiological aspects of soccer refereeing performance and training. Sports Med 2007; 37; 625-646

9 D'Ottavio S, Castagna $C$. Physiological load imposed on elite soccer referees during actual match play. J Sports Med Phys Fitness 2001; 41: $27-32$

10 Gilis B. Weston M, Helsen WF, Junge A, Dvorak J. Interpretation and application of the Laws of the Game in football incidents leading to player injuries. Int J Sport Psychol 2006; 37: 121-138

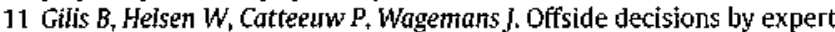
assistant referees in association football: Perception and recall of spatial positions in complex dynamic events. J Experimental Psych Appl $2008 ; 14: 21-35$

12 Helsen $W F$, Bultynck JB. Physical and perceptual-cognitive demands of top-class refereeing in association football. J Sports Sci 2004; 22: 179-189

13 Helsen $W$, Gilis $B$, Weston $M$. Errors in judging "offside" in association football: Test of the optical error versus the perceptual flash-lag hypothesis. J Sports Sci 2006; 24: 521-528

14 Krustrup P, Bangsbo J. Physiological demands of top-class soccer refereeing in relation to physical capacity: effect of intense intermittent exercise training. J Sports Sci 2001; 19: 881-891

15 Krustrup P. Mohr M, Bangsbo J. Activity profile and physiological demands of top-class soccer assistant refereeing in relation to training status. ] Sports Sci 2002; 20: 861-871

16 Krustrup P, Mohr M, Amstrup T, Rysgaard T, Johansen J. Steensberg A, Pedersen PK, Bangsbo J. The Yo-Yo Intermittent Recovery Test: Physiological response, reliability and validity. Med Sci Sports Exerc 2003; 35: 697-705 
17 Mallo J. Navarro E. García-Aranda $M$, Helsen W. Activity profile of top-class association football referees in relation to fitness test performance and match standard. J Sports Sci 2009; 27: 9-17

18 Mallo J, Navarro E, García-Aranda JM, Gilis $B$, Heisen W. Activity profile of top-class association football referees in relation to performance in selected physical tests. J Sports Sci 2007; 25: 805-813

19 Malio J, Navarro E, Garcia-Aranda JM, Gilis B, Helsen W. Analysis of the kinematical demands imposed on top-class assistant referees during competitive soccer matches. ] Strength Cond Res 2008; 22; 235-242

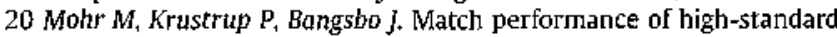
soccer players with special reference to development of fatigue. J Sports Sci 2003; 21 : 519-528

21 Reilly $T$. Energetics of high-intensity exercise (soccer) with particular reference to fatigue. ] Sports Sci 1997; 15:257-263

22 Reilly $T$, Bowen $T$. Exertional costs of changes in directinal modes of running. Perceptual Motor Skills 1984; 58: 149-150
23 Reilly $T$, Gregson $W$. Special populations: the referee and assistant referee. J Sports Sci 2006: 24: 795-801

24 Thomas JR, Nelson JK. Research methods in physical activity. [linois: Human Kinetics; 2001

25 Weston M, Bird S, Helsen W, Nevill A, Castagna C. The effect of match standard and referee experience on the objective and subjective mach workload of English Premier League referees. ] Sci Med Sport 2006; 9: 256-262

26 Weston M, Castagna C, Impellizzeri FM, Rampinini E, Abt G. Analysis of physical match performance in English Premier League soccer referees with particular reference to first half and player work rates, ] Sci Med Sport 2007; 10: 390-397

27 Woltring HJ. On optimal smoothing and derivate estimation from noisy displacement data in biomechanics. Human Mov Sci 1985; 4 $229-245$ 